\title{
Izquierda popular y feminismo en un cruce de caminos: el Espacio de Mujeres del Frente Popular Darío Santillán
}

\author{
Cristina Viano \\ Universidad Nacional de Rosario, Argentina - Asociación de Historia Oral de la República Argentina - \\ Centro Latinoamericano de Investigaciones en Historia Oral y Social - \\ crisviano@gmail.com \\ ORCID: 0000-0003-4143-6356
}

Titulo: Popular left and feminism at a crossroads: the Darío Santillán Popular Front Women's Space

Resumen: ¿Cómo se ha producido el enlace entre izquierdas y feminismos en un territorio distinto al de los partidos de cuño marxista leninista? Este artículo se interroga sobre la experiencia desplegada por el Espacio de Mujeres que nació en la Anibal Verón y se prolongó y multiplicó posteriormente en el Frente Popular Darío Santillán (FPDS) para analizar cómo y de que modos se fueron abriendo paso desobediencias que aunaron un cuestionamiento al orden de género patriarcal y al orden capitalista al interior de un movimiento socioterritorial multisectorial habitado principalmente por desocupados.

Palabras clave: militancia - espacio de mujeres - feminismo - antipatriarcal

Abstract: How the link between the left and feminism developed in a territory other than that of the Marxist-Leninist parties? This article is about the experiencia displayed by the "Women's Space" whose origin was the Anibal Veron and wich expanded in the Dario Santillán Popular Front. Our research analyzes how and what ways disobedience that joined a questioning of order patriarchal

DOI: https://doi.org/10.46688/ahmoi.n19.329

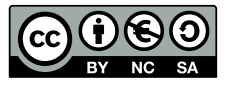

Obra bajo licencia Creative Commons 4.0 International (Atribución - NoComercial - Compartirlgual) 
gender and the capitalist order within a multisectoral socio-territorial movement inhabited mainly by unemployed people.

Keywords: militancy - women's space - feminism - antipatriarchal

Recepción: 28 de julio de 2021. Aceptación: 14 de agosto de 2021

$$
* * *
$$

Algunos y algunas que se plantean como anticapitalistas no incorporan la lucha antipatriarcal y muchos feminismos sostienen que la pelea no es contra el capitalismo, sino primero contra el patriarcado [...] Nosotras queremos un feminismo que nos involucre a todos y a todas, que sea combativo, activo, antipatriarcal, anticapitalista, en las calles y por el cambio social.

Espacio de Mujeres del FPDS, 2007

¿Qué caminos debemos recorrer para poder explicar que el feminismo es, por primera vez en su historia, un movimiento social de masas en Argentina que posee la capacidad de atravesar partidos, sindicatos, movimientos sociales, espacios barriales y educativos, que ejerce un influjo modulador en la cultura, que interpela al sistema judicial y político, pero también a la vida íntima, personal y social? Este interrogante, que deviene del corazón del presente instalado como centro de gravedad, reclama vincularse a otros, cuyo intento de respuesta anima las páginas que siguen. ${ }^{1}$ Sabemos que la actual situación fue posibilitada por innumerables experiencias, entre las que se cuentan sin duda las de las izquierdas; ahora bien, ¿cómo se ha producido el enlace entre izquierdas y feminismos en un territorio distinto al de los partidos de cuño marxista leninista? Nos preocupamos por acercarnos a una experiencia pionera: la del Espacio de Mujeres (EM) que nació en la Anibal

1. Quiero manifestar mi fuerte agradecimiento al conjunto de mujeres que en dos momentos muy distintos compartieron sus historias, ya sea a través de entrevistas o en conversaciones, diálogos e intercambios más informales. Algunas aparecerán con su nombre y apellido y otras identidades serán resguardadas. Las primeras entrevistas se realizaron en 2011 y 2012, las últimas en 2021, ante un grabador entonces y por medio de una pantalla ahora. Las más antiguas devienen de encuentros grupales (realizados en colaboración con Mariana Bortolotti) gestados por propia decisión de las entrevistadas. Y no solo; ellas escogieron los lugares donde realizarlas y también quiénes participaban; todas activistas del FPDS de extracciones sociales y franjas etarias diversas. 
Verón y se prolongó y desarrolló posteriormente en el Frente Popular Darío Santillán (FPDS) para analizar cómo y de qué modos se fueron abriendo paso esas desobediencias que aunaron un cuestionamiento al orden de género patriarcal y al orden capitalista al interior de un movimiento socioterritorial multisectorial habitado principalmente por desocupados. Experiencia de un EM que llevó a toda una organización a asumirse antipatriarcal y feminista, aun cuando, como veremos, ello constituyó un proceso complejo e inacabado, al tiempo que un horizonte a promover hacia adentro y hacia afuera.

\section{Salir a las calles: feministas y movimiento de mujeres}

La coyuntura abierta por la transición a la democracia en los años 80 constituyó un renovado escenario para que el pequeño feminismo de las catacumbas que sobrevivió en dictadura y esa contracultura subterránea que promovió se pudieran manifestar abiertamente. En ese período, el protagonismo de las mujeres supuso entre otras acciones la salida del movimiento feminista a las calles y que muchos asuntos considerados históricamente de naturaleza privada ingresaran al espacio público. Una significativa materialización la encontramos el 8 de marzo de 1984, cuando la reinaugurada democracia abrazaba a los distintos colectivos de mujeres convocados por la Multisectorial de la Mujer a movilizarse por primera vez para celebrar esa fecha en el espacio público. Ese acto fue representativo del vínculo trazado entre feministas y mujeres que no se asumían como tales, entre mujeres que provenían de partidos políticos, gremios, asociaciones femeninas, organismos de derechos humanos y agrupaciones feministas, que con muchas reuniones previas lograban trabajosos acuerdos para poner un mojón en la interlocución con el estado e inaugurar así la construcción de una nueva agenda (Grammático, 2020).

Desde entonces se fue configurando, no sin obstáculos, un panorama de organización y de planteo de demandas y se lograron obtener importantes avances en el acceso a derechos. Consensuar los reclamos hacía que las demandas más radicales tuvieran que dejarse para momentos más adecuados, pero los grupos feministas pertenecientes o no a la Multisectorial los agitaban sostenidamente (Tarducci, 2019). También se sentaron las bases para los nuevos lenguajes y categorias con que más adelante se pondría nombre a situaciones silenciadas y extendidas por las que atravesaban las mujeres. Había asomado a la acción colectiva una generación de feministas (hoy son las "históricas" o "pioneras" del movimiento) que se caracterizó por haber tenido acceso (en su mayoría) a una importante capacitación cultural y profesional. Ese activismo se plasmó en heterogéneas instancias organizativas: tanto 
en la conformación de incipientes ONG, centros académicos y espacios de articulación como en experiencias marcadamente autónomas; sin embargo en los 80 eran muy pocas.

Los 90 implicaron un cierto estancamiento del impulso con que venían del periodo anterior, al tiempo que comenzaron a hacerse evidentes algunas de las diferencias que agitaban a distintos (y pequeños aún) colectivos de mujeres feministas, lo cual redundó en un proceso de fragmentación y atomización. Sin embargo, cuando el neoliberalismo arreciaba en América Latina -bajo gobiernos elegidos democráticamente- comenzaba el proceso de ensanchamiento y diversificación del movimiento amplio de mujeres y del feminismo. Para entonces la chilena Margarita Pisano (y tantas otras voces en el período) en el marco del VII Encuentro Feminista Latinoamericano y del Caribe de El Salvador (1993) de modo vociferante sentenciaba: "No haré política con mujeres racistas, clasistas, homofóbicas, o que no defiendan el derecho al aborto, no haré política con mujeres que adhieren al modelo neoliberal, porque el proyecto político de esas mujeres borra y negocia con el patriarcado nuestra potencialidad de cambio civilizatorio" (Morroni, 2006, p. 91). Expresaba la posición de las "autónomas" en el conflicto con las "institucionalizadas"; debate que si bien no tuvo la misma profundidad y significación en Argentina, sí sus reverberaciones y herencias, sus vasos comunicantes; pero nos interesa recuperarlo porque manifiesta una crítica al feminismo que pudo (y puede) dialogar e incluso integrarse a la gramática neoliberal colocando una demarcación muy clara en la posibilidad de generar acuerdos.

Entretanto, y como respuesta a la salvaje lógica neoliberal imperante, se gestaban en distintos espacios del territorio nacional novedosas experiencias de autoorganización que, surgidas de las más duras condiciones de vida, lograban construir espacios de resistencia alternativos al modelo dominante. Fue desde allí desde donde se moduló (principalmente) una doble transformación: la del movimiento amplio de mujeres y la del movimiento feminista. Conforme los movimientos sociales y las acciones de protesta se multiplicaban hacia la segunda mitad de la década del 90 y se convertían en una referencia constante de la vida cotidiana, las mujeres adquirian un intenso protagonismo en ese ciclo de conflictividad social que surgía en distintas regiones del país, dotando de nuevos registros simbólicos y políticos a un conjunto de organizaciones con contenidos ideológicos y politicos muy heterogéneos. Ampliación y diversificación pueden ser vocablos adecuados para marcar algunas de esas transformaciones que se operaron en el movimiento de mujeres cuando avanzaba la década y la altísima concentración de la riqueza, la desocupación masiva, la precarización laboral y el empobrecimiento sistemático mostraban su fase más dura. 
En términos de composición de clase, una nota distintiva fue el desborde de la antes mayoritaria participación de mujeres de sectores medios. Esa transformación ininterrumpida hasta hoy ha sido denominada por Laura Masson (2007) como "feministas en todas partes" y ha supuesto derivas de distinta naturaleza, ya que no solo las mujeres que comenzaron a nutrirlo daban cuenta de una gran heterogeneidad social y cultural sino que también las organizaciones que las albergaban se expandieron en modalidades y número y tendieron a configurar un universo más ancho y con límites más difusos. Esa connotación que se insinuaba en el feminismo adquiría una potencia plena en el movimiento amplio de mujeres.

De modo que, en torno a la rebelión del 2001, los movimientos sociales que habian surgido en los 90 estaban poblados mayoritariamente por mujeres; y ello no significó una mera presencia numérica o un simple dato a registrar, sino que dotaban de nuevos registros simbólicos y políticos a un conjunto de organizaciones muy heterogéneas. Es decir, al tiempo que crecía el protagonismo de las mujeres al interior de distintos movimientos sociales, ellas los transformaban, resignificaban y en ese proceso se transformaban a sí mismas no sin dificultades ni contradicciones. Como una nota sobresaliente dentro de distintos movimientos sociales y politicos se construían espacios de mujeres que cobraban fuerza y visibilidad (Viano, 2020). De esta heterogeneidad creciente del movimiento de mujeres tenemos claras evidencias en los Encuentros Nacionales de Mujeres (ENM). En Salta en el 2002 la presencia de piqueteras, asambleístas, sindicalistas, campesinas, indígenas, trabajadoras de fábricas recuperadas marcaba la consolidación de nuevas expresiones del activismo de las mujeres (Di Marco, 2011).

\section{El puente que nos parió. De la Anibal Verón al Frente Popular Darío Santillán}

Apenas se produjo la Masacre de Avellaneda que desató el gobierno peronista de Eduardo Duhalde el 26 de junio de 2002, la Coordinadora de Trabajadores Desocupados Anibal Verón (CTDAV) difundió una declaración dirigida a "todos los hombres y mujeres de nuestro pueblo". Denunciaba los fusilamientos por la espalda, la criminal represión estatal sobre el movimiento piquetero y el regreso de los métodos del terrorismo de Estado, pero también desplegaba sus líneas de acción.

Como contraparte de tanta mentira, cualquier cronista o ciudadano que se acerque a nuestros barrios se encontrará con una intensa labor comunitaria: guarderias, comedores, centros de panificación, talleres de trabajo y capacitación de oficios... Se toparán con asambleas democráticas cada semana, 
con talleres de formación y de educación popular... En esto estaban Maxi, en el MTD de Guernica, y Darío, en el Barrio La Fe del MTD de Lanús... en medio de la miseria y la opresión sembramos dignidad y rebeldía. ${ }^{2}$

En la segunda mitad de los 90 los movimientos piqueteros se constituyeron en protagonistas centrales de la protesta y la movilización popular. En ese universo, la Verón, creada en el 2000 como coordinadora de lucha autónoma, independiente del Estado, de la iglesia, los sindicatos y de los partidos políticos, se perfiló como representativa de una línea dura y no dialoguista distinta del "brazo piquetero" que estimulaban otras izquierdas partidarias. Nucleaba Movimientos de Trabajadores Desocupados (MTD) que adoptaban los nombres de los territorios en los que nacían. Estaba integrada principalmente por los MTD de Lanús, Solano, Florencio Varela y Almirante Brown; aunque rápidamente cada MTD tomó distintos rumbos. La autonomía, la horizontalidad y la democracia directa fueron principios rectores compartidos. ${ }^{3}$

Desde el asesinato de Darío Santillán y Maximiliano Kosteki, el 26 de cada mes el puente Pueyrredón se cortaba. Y alli envueltas en el humo de gomas quemadas algunas mujeres comenzaron a hacer su propia asamblea. Un grupo pequeño que venía muy estimulado por los debates del XVIII Encuentro Nacional de Mujeres (ENM) en Rosario tomó la iniciativa, frente a la mirada hostil de algunos de los compañeros que participaban de la coordinación de la Verón (Partenio, 2008). La mayoría no se reconocía como feminista, aunque ese no era el caso de Celina Rodriguez Molina, ${ }^{4}$ una de las impulsoras de la iniciativa: "Nuestras consignas eran "Trabajo, dignidad y cambio social" [...] Veía en esas compañeras lo que a mí me había pasado en el 88 cuando yo no entendia... si yo había entendido, a pesar que era línea dura de la lucha de clases solamente, por qué no lo iban a entender las compañeras" (Duanes y Korol, 2016, p. 259).

2. CTDAV, 30 de junio de 2002. https:/ / frentedariosantillan.org/index.php/category/ archivo/2000-2004/

3.. El MTD Solano fue el impulsor principal y por ese tiempo produjo una serie de intervenciones (en clave autonomista y situacionista) junto al Colectivo Situaciones pero en las que estaban por completo ausente los planteos y perspectivas de acción que aportarían las feministas al espacio. Luego de la Masacre de Avellaneda se retrajo al trabajo territorial y no participó en los cortes de los 26.

4. Celina provenía de la militancia de los años 70 en el Peronismo de Base-Fuerzas Armadas Peronistas. Ya en los 80 tomó contacto con grupos feministas autónomos y espacios de derechos humanos y a través de distintas experiencias y vínculos comenzó un trabajo de articulación entre feminismos y marxismos, en la Cátedra Virginia Bolten en La Plata y en el grupo Las Azucenas del que fue una de las socias fundadoras. 
¿Hablás en las asambleas? ¿Participás en los lugares de decisión de tu movimiento? ¿Quiénes son los que llevan la palabra? ¿En qué te sentís agredida por ser mujer? ¿Sabés cómo cuidarte en tus relaciones sexuales? ¿Decidiste sobre tu maternidad? ¿Te parece importante que haya un espacio de mujeres dentro de los MTD Anibal Verón? Estas fueron algunas de las preguntas que lanzaron a sus propias compañeras para incentivar el debate; es que la mirada a veces indiferente, a veces renuente que acompañaba a ese grupo no sólo era la de los varones sino también la de muchas compañeras de militancia. En un universo donde las urgencias cotidianas eran tantas, ¿ंcuánto tiempo nos vamos a "frenar" a charlar? recordaba haber pensado una entrevistada. Ya fuera porque habia que organizar la olla o porque había que responder a una represión, siempre había "algo más urgente". Sin embargo allí estaban esas compañeras que sembraban inquietud con sus preguntas y sostenian la necesidad de hacerse un tiempo para "juntarse y conversar"; así como hacian el esfuerzo para tener un espacio de formación: "bueno, hagamos el esfuerzo para juntarnos las mujeres". Carina plantea:

Había compañeras de todas las edades. Yo creo que las compañeras con una definición y una claridad de que había que organizar el espacio de mujeres eran las compañeras más grandes, pero un montón de compañeras jóvenes se fueron sumando y era como muy poderoso esto de "nos juntamos, nos sentamos en el puente y conversamos". Ese proceso fue generando mucha adhesión y muchas compañeras sumándose pero si yo tengo que pensar en las compañeras que referenciaban el espacio, eran todas compañeras que tenían una experiencia militante previa, ¿no? Algunas compañeras de los 70 y algunas compañeras de la lucha más de los 80 , de principios de los $90 . .^{5}$

Interesa recuperar de este relato el vínculo, el enlace cooperativo que puede apreciarse entre mujeres de distintas generaciones que traen al puente cargas experienciales diversas para ponerlas en una acción común. Pero también la significación que la entrevistada atribuye a las "compañeras más grandes" donde la franja etaria indica no simplemente una cuestión biológica sino un mayor recorrido militante. Militancias que se van transformando al calor de intercambios con grupos y mu-

5. Carina Lopez Monja se sumó a la Verón desde el MTD de Almirante Brown, cuando era estudiante, apenas un mes después de la Masacre de Avellaneda, luego al FPDS. Hoy tiene 39 años, es periodista y politóloga y madre de dos gemelos de cuatro años. Forma parte de una radio comunitaria del Frente en la Villa 2124 de Barracas. Entrevista de 2021. 
jeres feministas con las que van realizando aprendizajes y generando contactos.

Cuando asumió Néstor Kirchner el puente se seguía cortando por justicia por Dario y Maxi y por todo un conjunto de urgencias y reclamos. En una reunión con el nuevo presidente a la "que van todos compañeros, está la foto ahí. Son todos varones los que van..." (Carina) vuelven con la promesa de investigar la masacre, pero también con el pedido de "che bueno, aflojen un poco, paren de cortar el puente". Un sector de la Verón cede y alli se produjo una fractura donde, durante un breve lapso, "empezaron a salir dos Anibal Verón a la calle. Ellos se llamaban Anibal Verón, nosotros nos llamábamos Anibal Verón”. Las diferencias, donde se pusieron en juego modos de funcionamiento y el posicionamiento frente al gobierno nacional, originaron dos líneas: por un lado, el MTD Aníbal Verón que teniendo como eje al Partido de Florencio Varela agrupaba también a organizaciones territoriales de otras zonas del Gran Buenos Aires; y por otro lado, a los MTD organizados en torno a lo que se constituiria a principios de 2004 como Frente Popular Dario Santillán. ${ }^{6}$ Esas divisiones y reacomodamientos pueden enmarcarse en una trama de fragmentación que se torna muy acusada en diferentes organizaciones piqueteras a partir del 2003 con la asunción de Néstor Kirchner (Svampa, 2009).

El FPDS nació entonces a partir de la confluencia de organizaciones piqueteras, varias de ellas autonomistas, de organizaciones estudiantiles (con fuerte presencia en Rosario, Tucumán, Neuquén y Córdoba), obreras, un incipiente sector rural y grupos de intelectuales y trabajadores de la cultura de La Plata y Buenos Aires y por activistas de las redes de trueque y organizaciones vecinales, principalmente del noroeste. Si bien es complejo trazar la geografia del mosaico de organizaciones que lo compusieron, sí debemos destacar que un fuerte peso cuantitativo y cualitativo lo ocuparon las organizaciones de desocupados o piqueteras de Buenos Aires (Diaz Lozano, 2019). También la distancia que estableció con la izquierda partidaria, que prolongaba una tradición forjada en la Verón.

6. Si el surgimiento del Frente coincidió con el inicio del gobierno de Néstor Kirchner (2003-2007), su derrotero posterior lo hizo con el despliegue hegemonizado por la configurada vertiente kirchnerista al interior del peronismo. Y así como la Verón sufrió su primera fractura por el posicionamiento duro o dialoguista con Kirchner, la existencia del FPDS -y más en general las organizaciones piqueteras y territorialesse estructuró en buena medida en función del posicionamiento que tomaban con el gobierno. En el período que abordamos (2004-2013) el FPDS se ubicó en un campo autónomo desplegando posiciones críticas hacia el gobierno. No obstante, el proceso de fragmentación fue un acompañante permanente de su existencia y en 2013 se dividió en dos: el FPDS y el FPDS Corriente Nacional. 
Carina relata ese proceso de transformación de una coordinadora piquetera a constituirse como una organización multisectorial:

Nosotros éramos una organización exclusivamente piquetera de trabajo de los barrios, de MTD y empezamos la articulación con centros de estudiantes, algunas agrupaciones estudiantiles, algunos grupos culturales, bueno, compañeras feministas que eran parte de la organización pero que su militancia más prioritaria era la de género y que tal vez participaban de otros colectivos... Empezamos a abrirnos a un debate que en ese momento llamamos multisectorial... nos dimos todo un debate sobre esto, que multisectorial no eran muchas clases sociales, sino que tenía que ver con que el sujeto de lucha no estaba solo en los barrios, en el piquete y en el sector más humilde de la clase trabajadora por decirlo rápido, sino que también los estudiantes cumplían un rol fundamental, las organizaciones feministas cumplian un rol fundamental, los trabajadores "en blanco", “asalariados”...

El espacio de mujeres pervivió y se prolongó desde la experiencia de la Verón a la del FPDS, aunque lo cierto es que allí adquirió proyección, densidad, definición y mayor alcance práctico y organizativo. Ahora bien, es válido preguntarnos dadas las características del Santillán: ¿cómo se desarrolló esa experiencia al interior no solo del Frente sino dentro de los distintos espacios que lo integraron?

La asumida multisectorialidad del Frente también reverberó en la reconfiguración del Espacio de Mujeres, donde pueden identificarse distintas proveniencias y presencias: las de mujeres de los barrios vinculadas a las tomas de tierras y luchas por los planes sociales, las de mujeres jóvenes que se suman desde la militancia estudiantil universitaria y mujeres de edades diversas pero con militancia política en los 70, en grupos de derechos humanos posdictadura, o vinculadas al activismo feminista (Partenio, 2008). Advertimos asimismo que entre las jóvenes universitarias hay hijas de militantes setentistas que han militado en organismos de derechos humanos (H.I.J.O.S., principalmente) y también muchas otras impactadas por la rebelión del 2001 y sus estelas sucesivas.

Adelantemos que de modo semejante al movimiento feminista, cuya historia no puede trazarse de manera lineal y sin fisuras, contando solo avances y acumulaciones, dentro del FPDS la brecha que intentaron abrir las mujeres no supuso tampoco, ni aún entre las mismas mujeres, un camino sencillo u homogéneo. ${ }^{7}$ Asumirse como feministas y las

7. Vislumbrar cómo se cuela la reproducción de lógicas de poder patriarcal al interior 
definiciones frente al aborto entran en esa consideración. Pero no solo ello, como veremos.

\title{
Un camino recorrido y por recorrer: antipatriarcales y feministas
}

Ningún intento de trazar el derrotero del FPDS puede obviar ese 2007 cuando se declaró "antipatriarcal". Fueron la primera organización socio-territorial o aún política en hacerlo. Mara, ${ }^{8}$ por entonces estudiante de antropología, considera que ello fue

\begin{abstract}
un punto de partida para poder trabajar en serio, [...] no nos quedemos en la consigna única y que seduce al resto de las organizaciones.... creo que veníamos como muy sueltas, yo me acuerdo que muchas veces hablaba de "los y las" y los compañeros me miraban y se reían ... decirnos como antipatriarcales nos habilita por ahí a poder empezar a discutir todo eso que decían. Pero no es que hay algo garantizado por llamarnos de tal o cual forma.
\end{abstract}

Un punto de partida al que tampoco fue sencillo arribar, digámoslo. El FPDS ya había realizado dos campamentos nacionales de formación política con participación mixta, cuando el EM convocó al "primer campamento nacional de formación en género", "para y desde las mujeres", a principios del 2007 en Glew. Alli se discutió la idea y desde entonces se abocaron a la producción de cartillas formativas que se distribuyeron en las distintas organizaciones del Frente de cara al Plenario Nacional de la organización en Mar del Plata. El objetivo era plantar la discusión sobre "patriarcado/capitalismo/feminismo".

Carina, que no pertenecía al EM, desnuda con mucha sinceridad sus recuerdos sobre ese momento. En ellos aparecen entremezcladas sus reflexiones y sus sentimientos pasados y actuales.

Costaban mucho las definiciones. Después hubo un click, ya con Venezuela como horizonte pudimos ir recuperando algunas cuestiones de debate y de definición política mucho más claras, la construcción de poder popular, el socialismo del siglo XXI... Fueron como cosas que marcaron fuerte a la organización, pero

\footnotetext{
de la organización nos permite identificar una común matriz que atraviesa tanto a las mujeres del FPDS como a las militantes de las izquierdas partidarias del período (al respecto ver el artículo de Casola en este mismo dossier).

8. Entrevista de 2012. Mara había comenzado a militar desde muy chica en barrio Ludueña y en grupos de mujeres cuando se sumó al Pampillón y al EM del Frente, de donde se alejó hacia fines de 2012, por cuestiones personales.
} 
las compañeras plantean en el debate definir a la organización como antipatriarcal, la primera discusión fue... "está bien pero no le vamos a dedicar tantas horas al debate, compañeras. No tenemos tanto tiempo para ustedes"...Era horrible... Se inició con esa actitud... con esa actitud tan complicada por parte de los varones y algunas mujeres, pero permitió abrir una etapa nueva en la organización, ¿no? Yo creo que es eso.

También recuerda que, después del debate en que se toma la definición, se encuentra con las compañeras del EM "gritando de felicidad" y sostiene que entonces no pudo dimensionar lo que implicaba para ellas y para la organización, que pudo entenderlo mucho tiempo después. Habian dado la disputa y la habian ganado. Pero

en una organización con determinadas prioridades, jerarquías, varones que hablan siempre, pocas compañeras que hablan... Las compañeras dieron una pelea, la respuesta fue mala... La respuesta no fue "sí compañeras, discutamos". La respuesta fue mala y las compañeras se la bancaron igual, la sostuvieron y la ganaron.

No obstante, ese día las compañeras del EM no lograron que se aprobara una declaración a favor del aborto legal, seguro y gratuito. Esa propuesta generó una intensa controversia a pesar del empeño que pusieron en fundamentarla. Y si bien decidieron retroceder a la espera de ir generando otras condiciones de comprensión, no se fueron sin nada en ese importante terreno: arrancaron el compromiso de impulsar el debate sobre la despenalización del aborto en los distintos sectores y organizaciones del Frente.

En ese plenario también se resolvió garantizar la participación orgánica igualitaria entre varones y mujeres a través de la atención de niños / as durante las diferentes actividades de la organización y cumplir con los cupos de participación en actividades de formación; potenciar la lucha antipatriarcal a través de la multisectorialidad del FPDS; mantener el Espacio de Mujeres pero a la vez impulsar instancias mixtas que incluyeran diferentes identidades de género. También generar espacios donde los varones pudieran compartir problemáticas; modificar el lenguaje de canciones que significaran insultos para la mujer; incorporar en los documentos públicos y conversaciones las terminaciones "os/ as" para referirse a "compañeros y compañeras" y trabajar sobre la contención de mujeres que padecieran violencia doméstica (Cross y Partenio, 2011, p. 199).

Distintas entrevistadas sostuvieron que declararse antipatriarcal no fue pensado solo para compañeras con interés en trabajar las temáticas 
de género o para el espacio de mujeres de distintos territorios sino más bien como componente de la política y de las relaciones cotidianas al interior de la organización toda, como un modo de generar una política hacia adentro de la organización y también una clave identitaria hacia el afuera. No obstante ello, manifestaban una fuerte preocupación por no quedar escindidas de la organización; avanzar en tareas de género y hacerse militantes que trascendieran lo específico y "poder pertenecer a todas las discusiones y todos los ámbitos dónde estamos". ${ }^{9}$

La siguiente anécdota es muy reveladora. Cuando un grupo del Santillán integrado por once varones y cuatro mujeres visitó Venezuela, ciertas características del Frente eran muy conocidas y cuando llegaron, el reclamo para compartir las experiencias del Espacio de Mujeres se hizo muy potente. Lo paradójico fue que las compañeras que viajaron no pertenecían al Espacio de Mujeres ni se sentían feministas y debian responder sobre las prácticas de la organización en distintos medios de comunicación. La experiencia del EM del Frente se había convertido ya en una referencia que habia trascendido las fronteras nacionales.

Nuestras canciones, la mística de los encuentros [...]. Ellas venían de hacer el Primer Encuentro Nacional de Mujeres en Venezuela y estaban sorprendidas en realidad de cómo la organización Frente Dario Santillán no tenía tan presente el tema de género como a ellas se lo habían contado. ${ }^{10}$

¿Qué rol les correspondía desempeñar a los varones del Frente en la lucha antipatriarcal? ${ }^{11}$ Para empezar, formar parte de procesos de formación. Los siguientes campamentos nacionales se convirtieron en mixtos con la inclusión de "los compañeros". Ello generó no pocos debates en torno al cupo, al cumplimiento en la asistencia y al rol que se

9. Entrevista colectiva, 2011.

10. Entrevista colectiva, 2011.

11. Algunos militantes del frente participarian de la formación de la organización Varones Antipatriarcales. El colectivo, que no formó parte del Frente, nació en La Plata en el año 2009 y en el 2011 se replicó en Rosario. Bajo la consigna "Ni machos ni fachos" hicieron una de sus primeras apariciones en las calles de La Plata vistiendo polleritas el día de la no violencia contra las mujeres. Desde la Educación Popular, trabajaron en talleres y Encuentros Nacionales con el objetivo de cuestionar sus privilegios, sus prácticas y las masculinidades que se construyen en una sociedad patriarcal. "Nos proponemos antipatriarcales como horizonte, como perspectiva y como proceso"; es en el desafio de desandar la categoría de varones donde "aunamos nuestras prácticas contra el patriarcado y sus opresiones", sostenian. Si mantuvieron articulaciones varias, compartieron espacios físicos de reunión, instancias de formación y coordinaciones ante la agenda feminista y LGBTI. 
desempeñaba en ellos. Algunos reclamaron mayores cuotas de representación y dieron discusiones intensas hacia adentro. También pidieron que los varones que eran referentes participaran de esas instancias.

Otro problema recurrente lo constituyó la elección de tareas internas. Distintas entrevistadas admiten que costaba reconocer que ello suponía también una cuestión atravesada por el género.

Me acuerdo una discusión con la regional de Jujuy, todos los años los que se terminaban proponiendo para el estudio eran compañeras y los compañeros siempre tenian alguna tarea más importante que hacer o algo más importante, siempre, siempre se terminaba delegando en esas compañeras para poder encargarse de esos espacios, y a la hora de plantearlo como un problema y de visibilizarlo... (se escucha un sonido que remite a la queja). ${ }^{12}$

Una suerte de marca constitutiva destaca: trabajar desde la práctica misma "con las particularidades que nos atravesaban por ser mujeres" y a ello se abocaron en las distintas regionales después del Plenario. En ese recorrido debieron enfrentar distintos mecanismos de descalificación sobre ciertas decisiones generadas en el EM que no siempre eran bien recibidas por los varones militantes (y también por otras mujeres). “¿Dónde se tomó esa definición?”, “esa acción no es representativa del conjunto de la organización", "se mandan solas", "son inorgánicas", fueron algunas de las formas que ello asumía, sobre todo ante temas de gran complejidad, como por ejemplo en las intervenciones que propiciaban ante situaciones de violencia machista al interior de los movimientos, o también en relación a la militancia en favor de la legalización del aborto, considerablemente resistida dentro de las organizaciones (Fabbri, 2019, p. 160).

La politica performativa no solo alcanzaba a las definiciones antipatriarcales sino también a las intenciones de promover el feminismo dentro de la organización. Nuestro trabajo de campo con militantes de algunos de los principales núcleos configuradores del FPDS en Rosario ${ }^{13}$ nos indica que prácticamente ninguna de las mujeres que los integró llegó directamente desde el feminismo a la militancia en el frente. Hacerse feministas fue gestándose desde la organización que las contenía, de manera gradual y no sin dificultades y resistencias. Aunque

12. Entrevista colectiva, 2011.

13. Nos referimos a la agrupación estudiantil Santiago Pampillón-El Grito, que se desarrolló fuertemente en las facultades de Humanidades, Ciencia Política y Psicología de la Universidad Nacional de Rosario y al Movimiento 26 de Junio de Barrio Moreno. 
también admitieron que la existencia del EM, que fue cobrando forma y desarrollando experiencia, atrajo a muchas otras voluntades al Frente y a sus organizaciones de base. Pichu ${ }^{14}$ recuerda que: "Cuando yo me asumí feminista, porque también fue un pase, esto del patriarcado al feminismo... De una postura en contra de la opresión a un lugar por la positiva más programático y de cuestionamiento más estructural".

Convoca a nuestro presente el registro del armado de "Mala Junta"15 y cómo discutian con compañeros la pertinencia o no de construir un colectivo que se definiera feminista frente a la alternativa de denominarse colectivo de géneros o espacio de géneros.

Y nosotras decíamos no... poniendo la discusión del sujeto del feminismo y también la posibilidad de activar desde otras identidades que no sean solo la de mujer y ahí sí me acuerdo la discusión y que salimos a defender la palabra feminismo. Que era necesario para nosotras un posicionamiento político como organización que ya no solo teníamos que reivindicarnos antipatriarcales, sino reivindicar la construcción desde el feminismo ... estamos hablando de esto, hace 11 años nomás, pero otra vida semántica... Otro mundo semántico... espacios de géneros no daba, el feminismo es un posicionamiento sobre esos géneros, sobre las relaciones de esos géneros y eso es lo que también queriamos salir a disputar. ${ }^{16}$

Pudimos entrever que los relatos de "conversión" son muy frecuentes de encontrar entre mujeres que se denominan feministas (en este caso feministas populares o feministas en la izquierda popular, según distintas intervenciones) y que ello se presenta como un camino recorrido y a recorrer, como un devenir no exento de dudas y complejidades en el cual se destaca una suerte de cambio que va desde el interior y se proyecta hacia el afuera, hacia lo social y político y fundamentalmente que ello cobra sentido a través de lo que se ha denominado "lenguaje de las emociones". También advertimos que la generación de identidades colectivas actuó como un refuerzo organizacional brindando mayor

14. Se trata de Pilar Escalante, quien comenzó su devenir militante en el Frente Estudiantil Santiago Pampillón en la Facultad de Ciencia Política de la UNR, luego volcado fuertemente en el socorrismo durante ocho años. Actualmente se desempeña como Subsecretaria de Politicas de Igualdad del Ministerio de las Mujeres, Géneros y Diversidad de la Nación. Entrevista, 2021.

15. Así sin s. Ese nombre fue adoptado por el EM de Rosario. En un período posterior al analizado -con el armado de Patria Grande- se retoma el nombre y se pluraliza como "Malas Juntas".

16. Entrevista a Pilar Escalante, 2021. 
cohesión al grupo, sobre todo al interior de una organización como esta que hizo de la identidad todo en centro de debates, construcción y prefiguración.

En el movimiento la presencia de las mujeres fue mayoritaria de manera constante y, a medida que en los núcleos barriales del Frente se fueron complejizando las actividades comunitarias en relación con las necesidades y condiciones generadas por el contexto político y económico más amplio, pero también como fruto de esa articulación multisectorial, ello implicó un traspaso de lógicas "piqueteras a territoriales". Entonces las iniciativas se multiplicaron incluyendo capacitaciones en oficios, salud, talleres recreativos y culturales para jóvenes, niños/as, jornadas de formación política y en feminismo entre otros (Diaz Lozano, 2019, pp. 68-69).

Sin embargo, la participación de las mujeres en los barrios era altamente discontinua: "se retiran, vienen, se van", indica una entrevistada.

Otra característica predominante son los hogares monoparentales con jefa de hogar mujer (Partenio, 2008). El de Lita era uno de ellos. En vísperas de la inauguración de un espacio barrial en Moreno y del anuncio público del nombre que tomaría desde el 2011 el EM en Rosario: Colectivo Feminista Mala Junta, nos reunimos con un grupo. De las mujeres provenientes del barrio Moreno, Lita fue la más participativa. Cuando les preguntamos si habian militado antes de sumarse al Frente, de su relato emergió una constelación de situaciones y valoraciones; por una parte la construcción que hace sobre esas y esos militantes que provienen de otros sectores sociales, también su propia historia familiar y los debates que mantiene con sus hijos. Señaló que no tiene marido pero sí hijos y que uno de ellos (su hijo) se molestó por su entrada al movimiento, pero que luego también se integró. Ella tuvo mucho que ver en ello: "andá conmigo al movimiento y vas a ver que ahí vas a estar bien como estoy yo", recuerda haberle dicho una y otra vez. ${ }^{17} \mathrm{El}$ caso de Lita representaba algo "distinto" dado que en otros hogares de las compañeras

los maridos no quieren saber nada con que estén en una organización, con que discutan problemáticas de género. Partiendo

17. La vida de Lita se vio conmovida muy pronto cuando el 2 de enero de 2012, su hijo (el Mono) fue asesinado junto a dos militantes más (Jere y Patom) en una canchita de futbol que la organización había construido para que los jóvenes pudieran salir de las esquinas, de la droga, de las "cocinas", de los barras, de las bandas, de los punteros. En diciembre los tres habían participado del campamento nacional de jóvenes del FPDS. El triple crimen de Barrio Moreno o la Masacre de Moreno -primero cubierta como "ajuste de cuentas"- se convirtió en un caso paradigmático de la ciudad de Rosario para visibilizar el narcotráfico y la connivencia político-judicial y policial. 
de que se vayan de la casa a una asamblea, con los cuatro o cinco críos, que "quién los cuida y después me los traés sucios, no me das el mate cuando llego de hacer las changas" y demás, eso es como la mayor de las limitaciones, digamos. ${ }^{18}$

Subraya que en el barrio el "puterío" que hace que se supiera qué pasaba dentro de cada casa no estimulaba la participación de las mujeres, sobre todo el que se acercaran a contar sus problemas. Más dificultoso resultaba aún que lo hicieran las más jóvenes del barrio; "sobre todo porque son madres desde los $14,13,15$. A los 19 ya van a tener dos hijos y esto ya hace que por lo general no se acerquen al Movimiento o se acerquen muy de por fuera".

En la organización apareció con mucha claridad el desafio que se les planteó a estas mujeres con la división sexual tradicional del trabajo y del trabajo militante en líneas más generales. Para armar los locales ellas se pusieron a hacer las "tareas pesadas", agarraron palas y cucharas, aprendieron a hacer mezcla y se sentaron a discutir con los varones. Lita volvió sobre una idea fuertemente internalizada en muchas mujeres: "No sabíamos hacer nada nosotras... de albañilería no entendiamos, yo siempre pensé que eso era un trabajo de hombre y yo ahora me doy cuenta que no". Interesa destacar como asocia el "saber" a las tareas que se asignan a los varones. El camino de la experiencia colectiva con otras le mostró su error; aún a costa de su propia sobreexplotación. Porque esas mujeres que estaban "en todos lados" sumaron a las tareas de cuidado, sostenimiento y reproducción comunitaria muchas otras que les eran bastante ajenas pero necesarias. Tanto la distribución como el reconocimiento de las tareas fueron motivo de debate y reconfiguración aunque no siempre con alcances suficientes para equilibrar las desigualdades de género, aun cuando éstas eran conocidas y reconocidas conforme los procesos de discusión y formación fueron alcanzando mayor profundidad y extensión.

Interesa destacar que cuando se conformaron los espacios de mujeres en el FPDS una consigna de uso extendido era "cuando una mujer avanza, ningún hombre retrocede”. Casi una década más tarde, la interpelación hacia los varones se fue transformando hacia expresiones como "varón bonito es el que cuestiona sus privilegios". Retomando un planteo de Espinosa (2008), Fabbri (2019, p. 181) insiste en que con el tiempo se fue desplazando la idea de "armonía", complementariedad y no amenaza hacia los varones ("ningún hombre retrocede"), que se

18. Entrevista colectiva, diciembre de 2011. Después del asesinato de su hijo, Lita se abocó a luchar por justicia. Luego de la resolución del juicio (en diciembre de 2014) se alejó de la militancia. 
transmitía inicialmente hacia una progresiva interpelación y cuestionamiento directo hacia los varones en general y hacia los compañeros militantes en particular, en tanto portadores de privilegios de género.

El trabajo que desplegaron las mujeres para poner en discusión cuestiones públicas, privadas y políticas fue incesante. A ello no escapó un tema "pesado" si los había y los hay: el aborto. Distintas voces han admitido que costó mucho en la organización. Aun cuando en los espacios estudiantiles del frente la discusión parece haber cobrado ribetes más sencillos, durante largos años no se tomaba como un eje de significación. La siguiente anécdota que aporta Pichu ${ }^{19}$ es muy reveladora:

Teniamos un volante escrito por Luciana Seminara que tenía un ovillo de lana con dos agujas que decía "Ni para tejer escarpines, ni para abortar". Que lo teníamos en el armario de militancia. Cuando yo empecé a militar ya había un toco de esos volantes, los sacábamos para fechas específicas... los militábamos un par de dias, y los volvíamos a guardar. O sea, estaban y nunca se gastaban y nunca se reeditaba esa línea, pero bueno, entonces en un momento nos dimos un proceso de discusión -esto debe haber sido 2009, ponele, 2008, 2009de reafirmación de posicionamiento por el derecho al aborto. ${ }^{20}$

Distintos registros indican que cundió el estado de alarma dentro del Frente cuando el EM osó sacar las primeras declaraciones favorables al aborto. El argumento "las compañeras del barrio te matan" fue uno de los esgrimidos. Incluso más, cuando se organizó la Campaña Nacional por el Derecho al Aborto Legal, Seguro y Gratuito, el Frente no fue parte de ella. Fue una larga discusión hacia adentro y primero se posicionó el EM, luego lo trataron sucesivos plenarios para decidir entrar a la Campaña y formar parte de la Campaña. Para ello habían pasado algunos años desde el 2005.

Cuando comenzaba la nueva década, algunas compañeras de Mala Junta que habían conocido la experiencia pionera de la Colectiva Feminista La Revuelta de Neuquén comenzaron a armar un dispositivo de socorrismo en Rosario en articulación con militantes de ATE, de Socialismo Libertario y con algunas médicas residentes que conocían.

19. Entrevista, 2021.

20. Interesa señalar que la entrevistada comete un acto fallido al atribuir la autoría de ese volante a Seminara. Fallido comprensible y explicable ya que esa militante había librado una intensa y temprana batalla dentro del Pampillón-El Grito por la concurrencia a los ENM y por la legalización del aborto. Incluso más, hacia el 2006 se había alejado -temporariamente- de la agrupación, entre otras diferencias, por el tratamiento desfavorable de cuestiones de género. 
Ello fue discutido como Frente y se sopesaron los riesgos legales que podía implicar. Por ello, muy inicialmente no decían a qué organizaciones pertenecían. Pero sí hubo una decisión orgánica para que las compañeras participaran, aunque fue un trabajoso proceso donde hubo que construir y discutir mucho.

En uno de los primeros acompañamientos que realizaron en Rosario (a una compañera de una organización política cercana), le pidieron a una militante del Frente si podía extenderles una receta de misoprostol y se negó. Todavía era un momento en el cual las recetas se hacían a nombre de varones, por lumbalgia y con muchos recaudos. Y no les quedó más remedio que salir a recorrer farmacias para conseguirlo sin receta.

En un congreso de la FUA, cuando el dispositivo tenía ya "contundencia", a Pichu le presentaron un compañero de otra regional: ella se dirigía a intervenir en un panel de género y él en uno de movimientos sociales. Cuando le dijo que era socorrista la "chicaneó", diciéndole pequeño burguesa y que "las compañeras del barrio no abortan". El relato de la controversia que sostuvieron brevemente es muy clarificador de las perspectivas que forjaban algunos militantes sobre las mujeres de los sectores populares. Ella le espetó entonces:

Sí, mirá, las compañeras del barrio abortan porque yo las acompaño...vos no sabés lo que pasa, tus compañeras si abortan, pero no te lo pueden decir a vos. Lo que pasa es que vos las dejás solas. Por suerte estamos nosotras que las acompañamos, pero tus compañeras abortan y yo las ayudo a ocultártelo.

\section{¿Condenadas al éxito?}

Hay experiencias muy representativas cuantitativamente del conjunto social, pero hay otras, como el caso del FPDS que, a pesar de haber constituido un movimiento relativamente pequeño, si lo comparamos con otras expresiones socio-territoriales del período, son significativos porque algunos de sus despliegues pueden irradiar mucho más allá de sí mismos tal como lo hizo la innovadora experiencia del EM. Ideario y práctica al que las Condenadas al éxito, una banda de diez mujeres platenses del Santillán, le puso cuerpo, letra y música y dispersó en marchas, encuentros, fiestas y campamentos. Como aquel estribillo que al ritmo de "A desalambrar" de Daniel Viglietti se permitieron cantar entre muchas otras de sus creaciones y adaptaciones impugnadoras del patriarcado y decididamente feministas: "Aborto legal, aborto legal / que este cuerpo es mío, no es tuyo ni de él / ni del fiolo, ni del cura, ni del patrón, ni del juez". 
Nos hemos aproximado a la experiencia desplegada por el EM que nació en el seno de una coordinadora piquetera dura como la Verón y encontró mayor alcance, potencia y desarrollo en una organización territorial multisectorial como el FPDS. Destejimos sus hilos organizacionales, su genealogía y particularmente sus prácticas y definiciones en el período que llega hasta 2013 connotado por la autonomía y la abstención de participar en actividades electorales.

Una organización toda (y no solo el EM) que fue pionera en declararse antipatriarcal y feminista, sin ninguna duda. Sin restar mérito alguno a ello, hemos tratado de marcar que esas definiciones, promovidas por el $\mathrm{EM}$, se constituyeron no en un punto de llegada sino fundamentalmente en un horizonte a conquistar también hacia dentro de la organización. Por ello, y valiéndonos principalmente de testimonios de militantes del Frente mostramos cómo emergieron tensiones y dificultades; no fue un camino sencillo, lineal ni concluido.

Por otra parte, ningún balance que intente dar cuenta de la articulación entre izquierdas y feminismos puede obviar el papel fundamental que en el derrotero argentino ha jugado la experiencia metabolizada por las mujeres a lo largo de los ENM. La muy conocida expresión "no volvés igual" y otras similares adquirieron potencia plena (también) para las mujeres del Frente, pertenecieran o no al EM. Los intercambios que se produjeron con otras organizaciones y movimientos sociales latinoamericanos han sido muy relevantes: no solo los encuentros feministas latinoamericanos, sino el tejido de relaciones con el Frente Nacional Campesino Ezequiel Zamora de Venezuela y especialmente las experiencias que pudieron obtener en los viajes de formación a los campamentos del Movimiento Sin Tierra de Brasil, de los cuales las mujeres traían "las discusiones más feministas". También debemos jerarquizar el rol de las mujeres que con su empecinamiento empujaron la conformación del EM. Esa tarea inicial encontró interlocutoras sensibles en otras generaciones, en mujeres de distintos sectores sociales y con variados recorridos de vida. Ello marcó un exitoso camino donde se conjugaron transmisiones, apropiaciones, creaciones y persistencias.

Valoramos como una herramienta imprescindible de acceso a esa experiencia las voces de las mujeres del Santillán; la mayoría de ellas integrantes del EM. A partir de internarnos en sus relatos pudimos entrever que lo que las vinculaba al Frente no era solo la naturaleza de las reivindicaciones que se agitaban en su interior sino la forma en que se tramitaban y agenciaban colectivamente. Y ello acontecía particularmente en el EM. Tal vez convenga insistir en el hecho de que las entrevistadas dieron sentido a sus experiencias a través del relato; ese acto las estimuló a pensarse, a pensar una trayectoria y una historia; la propia y la común del colectivo. Un dato no menor es que en las entre- 
vistas afloró el cuestionamiento hacia el lugar de las mujeres al interior de Frente y que ello no aconteció por nuestra particular insistencia, no vimos alli intentos de ocultamiento sobre la vida interna de la organización. Sí pudimos vislumbrar con claridad cómo las mujeres que alimentaron el EM bregaron por relaciones intergéneros o bien igualitarias o por una división del trabajo militante no jerarquizada sexualmente, al tiempo que construyeron nuevas agendas no solo hacia afuera sino que fundamentalmente interpelaron a sus propios compañeros relanzando su protagonismo en innovadoras claves.

El EM primero de la Verón y luego del FPDS constituye una expresión muy acabada de un proceso que devino persistente y transformador en Argentina: la creación de espacios de mujeres dentro de distintos movimientos socio-territoriales y políticos. Podrá argumentarse que ello no era nuevo y que distintas organizaciones políticas en el pasado más cercano o más lejano lo habían ensayado: desde el Partido Comunista (Casola, 2014) al peronismo en los años 40 (Barry, 2009) o el Partido Comunista Revolucionario en los 80 pasando por la experiencia de distintas organizaciones de la nueva izquierda de los años 70. En éstas fue particularmente notorio que los objetivos estaban dirigidos principalmente a incorporar mujeres obreras y de sectores populares, que ello había sido una decisión de las cúpulas de las organizaciones y que las mujeres que los integraron (en los casos de la Agrupación Evita de Montoneros y del Frente de Mujeres del PRT-ERP) no creían que debiera realizarse un trabajo específico con las mujeres. Asimismo había cierta reticencia a participar de un espacio que las devolvia a una actuación separada y que entraba en tensión con la pregonada igualdad entre compañeros (Noguera, 2021).

Estos rasgos nos permiten establecer una distancia entre aquellos intentos y los que analizamos en este artículo, ya que tanto por el grado de generalización como por las prácticas y definiciones que comienzan a habitarlos y cobrar fuerza podemos sostener que se trata de experiencias que suponen un conjunto de rupturas y a distintas profundidades en relación con todas las ensayadas en forma precedente. La rebelión destituyente del 2001 fue una bisagra. Y alli fueron las mujeres las que realizaron un gesto fundante; se hicieron cargo de producir espacios de reproducción colectivos, saltaron masivamente del confinamiento doméstico desacoplado del régimen salarial y sobre esa trama se montó luego la economía popular que contribuyó a corroer la legitimidad política del neoliberalismo. Aquel ciclo no puede comprenderse sin el protagonismo femenino (Gago, 2019). Tampoco la experiencia del FPDS. Fue la agencia de las mujeres la que impulsó la creación de esos espacios. Esas mujeres comenzaron a dirigir sus cuestionamientos también a sus propios compañeros de militancia. 
Una entrevistada sostuvo que "hay que tener la humildad de asumir que una sigue aprendiendo a lo largo de los años, por más años de militancia que tenga y más experiencia y más viejo, vieja que sea... Y yo creo que eso... que el feminismo... cuando el Frente Darío Santillán se define antipatriarcal era revolucionario, ¿no? No habia ninguna organización todavía con tanta claridad. Pero poder trabajarlo, el aborto por ejemplo, discutirlo con la última compañera de un barrio popular, se dio con la revolución de las pibas... No se dio antes". Pero ello fue posible, advertimos, porque el camino ya estaba sembrado.

\section{Bibliografía}

Barry, C. (2009). Evita Capitana. El partido Peronista Femenino, 1949-1955. Eduntref.

Casola, N. (2014). Con "m" de "mamá": las militantes comunistas y la Unión de Mujeres Argentinas durante la segunda mitad del siglo XX. Amnis, 13. Disponible en http://journals.openedition.org/amnis/2097. DOI: https://doi.org/10.4000/amnis.2097.

Cross, M.C. y F. Partenio (2011). ¿Cuál cambio social? construcción de vínculos políticos en un espacio de mujeres piqueteras. Punto Género, 1, 4. Disponible en http://hdl.handle.net/11336/8461.

Díaz Lozano, J. (2019). Mujer bonita es la que sale a luchar: Experiencias de vida de mujeres participantes del Frente Popular Darío Santillán Corriente Nacional de Berisso. Tesis de posgrado. Universidad Nacional de La Plata. Disponible en: http:/ /www.memoria.fahce.unlp.edu.ar/tesis / te. $1800 /$ te. $1800 . p d f$.

Di Marco, G. (2011). El pueblo feminista. Movimientos sociales y lucha de las mujeres en torno a la ciudadanía. Biblos.

Duanes L. y C. Korol (2016). Las mujeres del Frente. Relato a dos voces: Celina Rodríguez Molina y Adriana Pascielli, la Tana. En C. Korol (comp.), Feminismos populares. Pedagogias y politicas. América Libre-Chirimbote-El Colectivo.

Espinosa, C. (2008). Cuando una mujer avanza ningún hombre retrocede o ¿hasta dónde llega la ideología de la armonía? IX Congreso Argentino de Antropología Social. Universidad Nacional de Misiones, Posadas.

Fabbri, L. (2019). La co-producción de narrativas feministas como método-proceso para el desprendimiento androcéntrico. Tesis doctoral, Facultad de Ciencias Sociales, UBA.

Gago, V. (2019). La potencia feminista. O el deseo de cambiarlo todo. Tinta Limón.

Grammático, K. (2020). El 8 de marzo de 1984. Notas para una historia reciente del feminismo argentino. En K. Grammático, A. Valobra y D. D’Antonio (comps.). Historia de las mujeres en la acción política. De la revolución rusa a nuestros dias. Imago Mundi. 
Masson, L. (2007). Feministas en todas partes. Una etnografia de espacios y narrativas feministas en Argentina. Prometeo.

Morroni, L. (2006). Constitución del Movimiento Feminista Latinoamericano y del Caribe en torno al debate "autónomas" vs. "institucionalizadas". Actos performativos e identidad. Tesis de Maestria, Universidad Nacional de Rosario.

Noguera, A. (2021) Las chichises se organizan: militancia en los frentes de mujeres del PRT-ERP y Montoneros (Córdoba, 1973-1974). Anuario, 34. Escuela de Historia, UNR. Disponible en http://anuariodehistoria.unr. edu.ar/ojs/index.php/Anuario/index.

Partenio, F. (2008). Género y participación politica: Los desafios de la organización de las mujeres dentro de los movimientos piqueteros en Argentina. Informe final del concurso "Las deudas abiertas en América Latina y el Caribe”. Programa Regional de Becas CLACSO. Disponible en: http:/ / bibliotecavirtual.clacso.org.ar/ar/libros/becas/2008/deuda/partenio.pdf.

Svampa, M. (2009). Postfacio. En M. Svampa y S. Pereyra. Entre la ruta y el barrio. La experiencia de las organizaciones piqueteras. Biblos.

Tarducci, M. (2019). Los años 80. En M. Tarducci, C. Trebisacce y K. Grammático, Cuando el feminismo era mala palabra. Algunas experiencias del feminismo porteño. Espacio.

Viano, C. (2020). El movimiento feminista tiene historia: una mirada desde el Encuentro Nacional de Mujeres. En K. Grammático, A. Valobra y D. D’Antonio (comps). Historia de las mujeres en la acción politica. De la revolución rusa a nuestros dias. Imago Mundi. 